Génét. Sél. Evol., 1987, 19 (1), 9-20

\title{
Segregation of blood group factors in horses with special reference to maternal-fetal incompatibility
}

\author{
K. SANDBERG and L. ANDERSSON \\ Department of Animal Breeding and Genetics, Swedish University of Agricultural Sciences \\ S-750 07 Uppsala, Sweden
}

\begin{abstract}
Summary
Segregation data on 15 blood group factors from 32,403 complete horse families were analysed. The horses belonged to the Swedish Trotter (ST) breed and the North-Swedish Trotter (NST) breed. The distribution of offspring from matings of sires heterozygous for a blood group factor and dams lacking the factor (incompatible matings) as well as from the reciprocal matings of heterozygous dams and negative sires (compatible matings) were analysed. In general, there was good agreement between observed and expected segregation ratios. The extensive data available enabled the detection of even minor deviations from expectation. The most interesting observations were (a) an cverall excess of heterozygous offspring from both types of matings in the ST breed and (b) a deficit of heterozygous offspring from incompatible matings for several factors in the NST breed. Possible explanations for these deviations from expected segregation ratios are discussed. There was no indication of a maternal-fetal incompatibility with regard to $\mathrm{Aa}$ and $\mathrm{Qa}$, the two factors known to be involved in the great majority of cases of neonatal isoerythrolysis in the horse.
\end{abstract}

Key words : Horse, blood group factor, segregation analysis, maternal-fetal incompatibility.

\section{Résumé}

Ségrégation de facteurs sanguins chez le cheval en relation avec l'incompatibilité foeto-maternelle

Les ségrégations de 15 facteurs sanguins dans 32403 familles complètes de chevaux sont analysées. Les chevaux appartiennent à la race du Trotteur suédois (TS) et à celle du Trotteur du Nord de la Suède (TNS).

La distribution de la progéniture de pères hétérozygotes pour un facteur sanguin et de mères ne possédant pas ce facteur (accouplements incompatibles) et de celle résultant d'accouplements réciproques entre mères hétérozygotes et pères négatifs (accouplements compatibles) est analysée. Dans la plupart des cas, il y a une bonne concordance entre les rapports de ségrégation observés et attendus.

Les nombreuses données disponibles permettent de détecter des écarts très minimes par rapport aux résultats prévus. Les observations les plus intéressantes sont : (a) un excès global d'hétérozygotes chez les produits des 2 types d'accouplements dans la race TS et (b) un déficit d'hétérozygotes chez les produits d'accouplements incompatibles pour plusieurs facteurs dans la 
race TNS. Les explications possibles de ces écarts avec les rapports de ségrégation prévus sont discutées. Il n'y a aucune indication d'incompatibilité fơto-maternelle en ce qui concerne les facteurs $\mathrm{Aa}$ et Qa, les 2 facteurs qu'on sait être impliqués dans la grande majorité des cas d'isoérythrolyse néo-natale chez le cheval.

Mots clés : Cheval, facteur sanguin, analyse de ségrégation, incompatibilité fæeto-maternelle.

\section{Introduction}

Segregation data are commonly used to test theories on the mode of inheritance of new genetic systems or new blood group factors. If Mendelian inheritance of a system or factor is assumed, segregation analysis, applied to a substantial set of family data, provides a measure of differences in viability or fertility between phenotypes. Possible selective forces affecting blood group genes are in general bound to be weak, which means that very large amounts of data are required to make it possible to reveal them. With a few exceptions (e.g. SмIтH et al., 1968) extensive bodies of segregation data have not previously been analysed in farm animal species. However, both from an evolutionary and animal breeding point of view it is of importance to gain information on the selective forces which may influence the frequency of blood group genes in farm animals.

One possible cause of differential viability is immunological incompatibility between blood types of mother and offspring. The human $\mathrm{Rh}$ blood group system is a wellknown example of this phenomenon. Erythroblastosis foetalis, caused by incompatibility of maternal and fetal $\mathrm{Rh}$ blood types, was a serious source of fetal death in man before an adequate prophylaxis and therapy was developed.

In the horse a homologous disease called neonatal isoerythrolysis (NI) has been known for a long time (CARoli \& Bessis, 1947 ; Bruner et al., 1948 ; CoOmbs et al., 1948). In this disease the foal's red blood cells (RBC) are destroyed by maternal anti$\mathrm{RBC}$ antibodies. The deleterious antibodies are produced by the mare in response to one or more red cell antigens which the foal has inherited from the sire, and which are absent in the mare. The antibodies are transmitted to the foal through colostrum which is considered the exclusive route of passive immunity from mare to foal. The first NI foal is usually delivered by a mare in the fourth to seventh pregnancy, although NI among foals from earlier parities has been observed (FraNKS, 1962).

The available overall data on NI in horses indicate that the blood group factors Aa of the $A$ system and $Q$ a of the $Q$ system are the 2 antigenic determinants involved in the great majority of cases (Stormont, 1975 ; Suzukı, 1978 ; Balley, 1982). Only very rarely have other blood factors been found to provoke the formation in pregnant mares of antibodies deleterious to the newborn foal (ScOTT \& JEFFCOTT, 1978; NodA \& WATANABE, 1975).

Since NI is not a contagious disease the cases that occur are rarely reported. It is also likely that some deaths due to NI are incorrectly diagnosed as due to infectious agents with similar effects. These circumstances make it very difficult to obtain a good estimate of the incidence of NI in any population of horses. CRONIN (1955) estimated the frequency of NI among Thoroughbred foals in England to be about 1 p. 100 on the basis of a case study. In a more recent survey in Kentucky, BAILEY (1982) found that 1 
p. 100 (4 out of 409) of Thoroughbred mares and 2 p. 100 (8 out of 390) of Standardbred mares had antibodies which could have caused NI had colostrum not been withheld from the foals.

In the present study segregation data on 15 blood group factors in an extensive collection of horse families were examined. The object was to look for possible distorted segregation ratios and in particular to see if any indication of the well-known maternal-fetal incompatibility with respect to certain blood group factors could be found. A preliminary report on this study was given at the 19th Conference of the International Society for Animal Blood Group Research (SANDBERg \& ANDERsson, 1985).

\section{Materials and methods}

The horse material used in the present study and the blood typing tests applied are described elsewhere (SANDberg \& Andersson, 1984). Altogether 26,900 complete families (sire, dam and offspring) of the Swedish Trotter (ST) breed and 5,503 families of the North-Swedish Trotter (NST) breed were available for the study. Each horse was tested for the following 15 blood group factors: Aa, Ab, Ac, Ca, Da, Db, Dc, Dd, $\mathrm{De}, \mathrm{Df}, \mathrm{Ka}, \mathrm{Pb}, \mathrm{Qa}, \mathrm{Qb}$ and $\mathrm{Qc}$. All offspring had passed parentage tests with a mean probability of 0.90 of detecting a falsely assigned parent (SANDBERG, 1974). The great majority of offspring were investigated at an age of 4-18 months.

For each blood group factor the distributions of progeny from the mating of heterozygous sires and negative dams $\left(+I-\sigma^{\top} \times-1-q\right.$; incompatible matings) and from the reciprocal mating of heterozygous dams and negative sires $\left(-1-\sigma^{\prime} \times+1-Q\right.$; compatible matings) were examined. The heterozygosity of a sire was inferred from the occurrence in his progeny group of at least one offspring lacking the factor. For the matings between heterozygous sires and negative dams only sires having at least 10 offspring from such matings were included. With such large progeny groups equal numbers of heterozygous and negative offspring are expected when the sires are selected in this way.

The heterozygosity of a dam was inferred either from the blood type of its parents or from the occurrence of at least one $-l-$ offspring in matings with $+/-$ or $-l-$ sires. In the cases when the heterozygosity was inferred from the parent's blood type or from the occurrence of $-I-$ offspring in matings with $+/-$ sires, all such dams with one or more offspring were included in the analysis. As the inference on heterozygosity in these cases was based on information not used in the segregation analysis, equal numbers of $+/-$ and $-1-$ offspring are expected. In the cases when the heterozygosity was inferred from the occurrence of $-1-$ offspring in matings with $-/-$ sires, only dams having at least two offspring from such matings were included. The expected proportions of $+1-$ offspring from this type of matings were computed according to the a priori method of BERNSTEIN (1929), separately for dams with progeny groups of two, three, four, etc. offspring. For each factor, observed and expected numbers of $+/-$ and -1 - offspring were added over all these categories of dams.

In order to make out if a possible departure from Mendelian ratios due to maternal-fetal incompatibility appeared, if it was assured that the dam had had a 


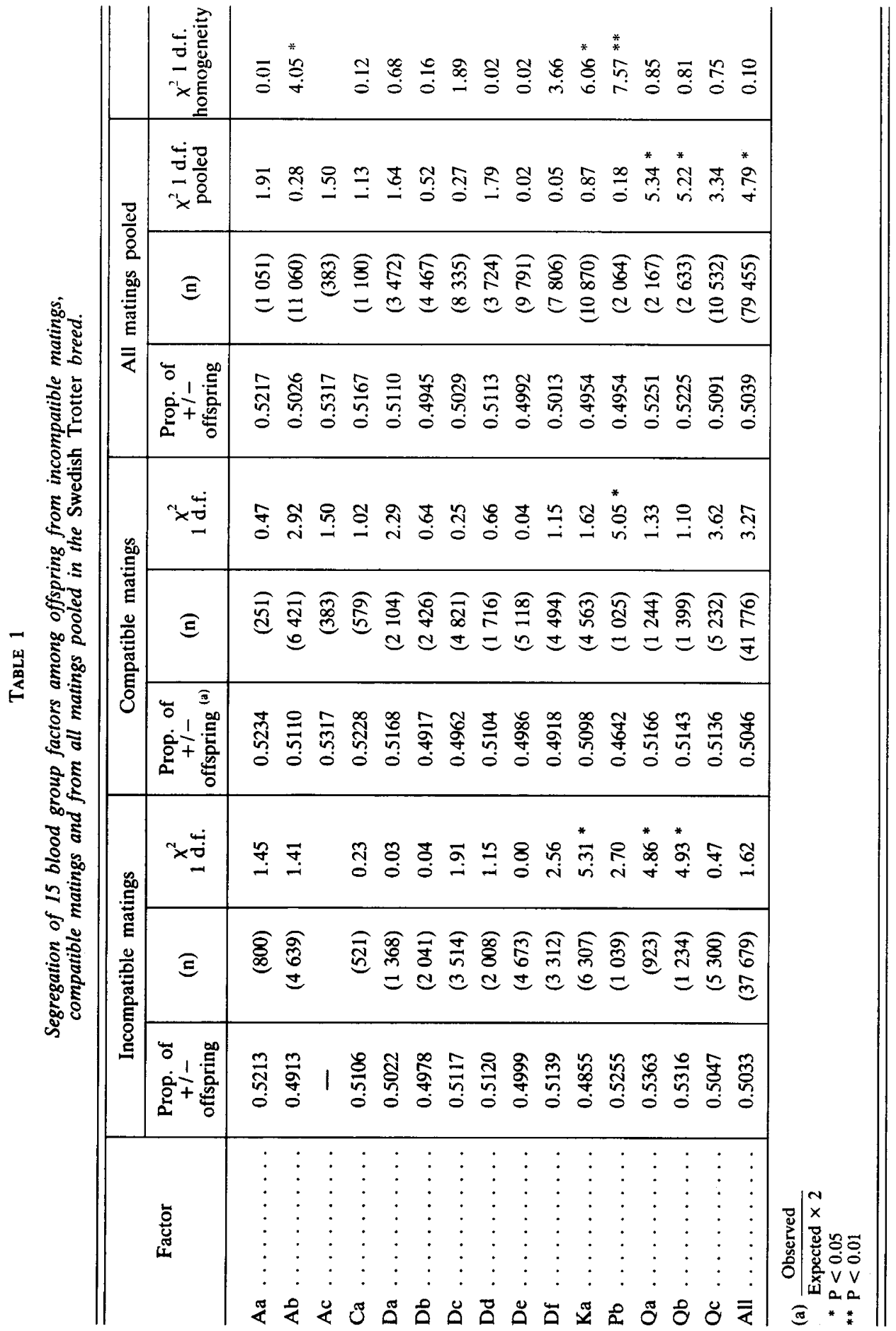




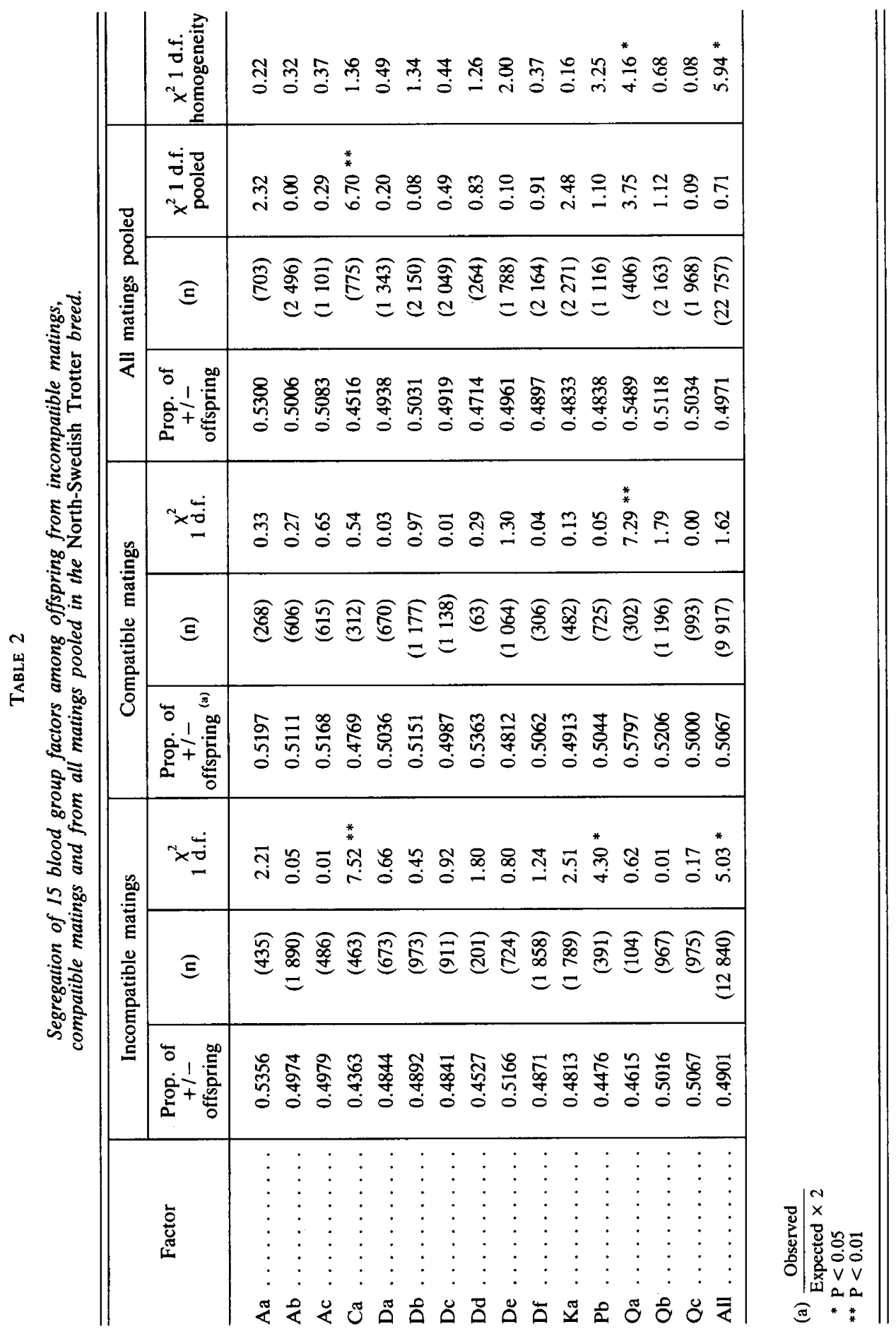


possibility to become sensitized to the factor studied, we excluded from the progeny group of each mare the offspring from the first incompatible pregnancy $(-1-$ mare with a $+/-$ offspring) in the period studied (1970-1979) and all offspring born prior to that. Several mares involved had offspring born before 1970 , so some older mares most likely had had two or more offspring from incompatible pregnancies before the offspring included in this part of the study were born.

For each factor a chi-square was calculated from the observed and expected numbers of $+/-$ and $-/-$ offspring from incompatible matings, compatible matings and when offspring from the 2 types of matings were pooled. The segregation ratios from compatible and incompatible matings were compared by homogeneity chi-square tests. These chi-squares were also calculated for offspring pooled over factors. All calculations were carried out separately for the ST and NST breeds.

\section{Results}

In table 1 is shown a summary of data on the segregation of each of 15 blood group factors in the ST breed. For the sake of simplicity the proportion of $+/-$ offspring is indicated instead of the actual numbers of heterozygous and negative offspring. Segregation ratios are given for offspring from incompatible matings, from compatible matings and for offspring pooled over mating types.

The chi-square values obtained when testing the agreement between observed and expected segregation ratios are given in the table as well as those obtained when comparing the data on compatible and incompatible matings by homogeneity chi-square tests.

When observed and expected numbers of offspring were pooled over factors and mating types, representing no less than 79,455 matings between one heterozygous and one negative parent, there was a significant excess of heterozygous offspring $(P<0.05)$. This deviation did not appear to be due to one or a few individual factors but rather to a general tendency among most factors towards a slight excess of heterozygous offspring; the proportion of heterozygous offspring exceeded 0.50 for 10 out of 14 factors among incompatible matings, for 10 out of 15 factors among compatible matings and for 11 out of 15 factors in the pooled data. This effect seemed, however, to be most pronounced for the factors $\mathrm{Qa}$ and $\mathrm{Qb}$ which had a slight excess of $+1-$ offspring in both mating types, resulting in significant pooled chi-squares for both. The tests on Qa and $\mathrm{Qb}$ were not quite independent as in this material $\mathrm{Qa}$ does not occur except in the allele $Q^{a b c}$. Furthermore the allele $Q^{b}$ has a low frequency in the ST breed. Also Qc had an almost significant excess of heterozygotes. Three factors, $\mathrm{Ab}, \mathrm{Ka}$ and $\mathrm{Pb}$ exhibited significant homogeneity chi-squares (table 1) indicating differences in segregation ratios between incompatible and compatible matings. All other factors in the ST breed segregated according to expectation in both types of matings.

Table 2 shows the corresponding distribution of offspring in the NST breed. In this breed there was a significant $(\mathrm{P}<0.05)$ deficit of heterozygous offspring from incompatible matings when data were pooled over all factors. On the contrary a slight excess of $+/-$ offspring appeared in compatible matings. Therefore the homogeneity chi-square reached significance at the 5 p. 100 level suggesting a small maternal-fetal incompatibi- 
lity effect from several factors. One individual factor alone, namely $Q$ a, gave a significant homogeneity chi-square resulting from a highly significant $(P<0.01)$ excess of $+1-$ offspring in compatible matings and a small deficit in incompatible matings. The Ca factor gave a highly significant $(\mathrm{P}<0.01)$ deficit of $+/-$ offspring in incompatible matings and a small deficit in compatible matings. This resulted in a highly significant $(\mathrm{P}<0.01)$ pooled chi-square for $\mathrm{Ca}$.

At a closer inspection of the segregation of individual factors it appeared that $\mathrm{Aa}$ gave a small excess of $+/-$ offspring in both types of matings in both breeds. When offspring were pooled over breeds and mating types this excess proved to bê significant $\left(X_{1}^{2}=4.14 ; \mathrm{P}<0.05\right)$. Also the factors $\mathrm{Qa}$ and $\mathrm{Qb}$ gave significant $\left(\chi_{1}^{2}=8.35 ; \mathrm{P}<0.01\right.$ and $\chi_{1}^{2}=5.78 ; \mathrm{P}<0.05$ respectively) excesses of heterozygotes when all data were pooled, while for Qc the excess was only close to significance $\left(\chi_{1}^{2}=3.22 ; \mathrm{P}<0.10\right)$. All other factors segregated according to expectation in this respect (results not shown).

TABLE 3

Proportion of $+1-$ offspring from matings of $+1-$ sires and $-1-$ dams with regard to 15 blood group factors in two horse breeds. Only offspring of dams with at least one prior incompatible pregnancy are included (see text).

\begin{tabular}{|c|c|c|c|c|c|c|}
\hline \multirow[b]{2}{*}{ Factor } & \multicolumn{3}{|c|}{ ST breed } & \multicolumn{3}{|c|}{ NST breed } \\
\hline & $\begin{array}{l}\text { No. of } \\
\text { matings }\end{array}$ & $\begin{array}{c}\text { Prop. of } \\
+l- \\
\text { offspring }\end{array}$ & $\begin{array}{l}x^{2} \\
1 \text { d.f. }\end{array}$ & $\begin{array}{l}\text { No. of } \\
\text { matings }\end{array}$ & $\begin{array}{c}\text { Prop. of } \\
+1- \\
\text { offspring }\end{array}$ & $1 \stackrel{\chi^{2}}{\text { d.f. }}$ \\
\hline Aa & 504 & 0.5198 & 0.79 & 222 & 0.5360 & 1.15 \\
\hline$\ldots \ldots \ldots$ & 1660 & 0.4927 & 0.35 & 660 & 0.4803 & 1.02 \\
\hline$\ldots \ldots \ldots$ & & & & 81 & 0.5185 & 0.11 \\
\hline$\ldots \ldots \ldots$ & 325 & 0.4953 & 0.03 & 207 & 0.4347 & 3.52 \\
\hline Da $\ldots \ldots \ldots \ldots$ & 296 & 0.5472 & 2.65 & 94 & 0.4893 & 0.04 \\
\hline Db $\ldots \ldots \ldots \ldots \ldots$ & 434 & 0.4976 & 0.01 & 240 & 0.5166 & 0.27 \\
\hline Dc. & 1766 & 0.5220 & 3.45 & 297 & 0.4983 & 0.00 \\
\hline$\ldots \ldots \ldots \ldots$ & 1312 & 0.5152 & 1.22 & 105 & 0.4952 & 0.01 \\
\hline $\mathrm{De} \ldots \ldots \ldots \ldots$ & 1336 & 0.5134 & 0.97 & 277 & 0.5270 & 0.81 \\
\hline Df $\ldots$ & 859 & 0.5122 & 0.51 & 577 & 0.4644 & 2.91 \\
\hline$\ldots \ldots \ldots$ & 2947 & 0.4903 & 1.10 & 561 & 0.4955 & 0.04 \\
\hline $\mathrm{Pb} \ldots$ & 146 & 0.5342 & 0.68 & 75 & 0.4400 & 1.08 \\
\hline$\ldots \ldots \ldots \ldots$ & 209 & 0.5311 & 0.81 & 22 & 0.3181 & 2.91 \\
\hline Qb .... & 282 & 0.5354 & 1.42 & 321 & 0.5046 & 0.03 \\
\hline Qc. $\ldots \ldots \ldots \ldots$ & 2118 & 0.4943 & 0.27 & 259 & 0.4671 & 1.12 \\
\hline All $\ldots \ldots \ldots \ldots$ & 14194 & 0.5054 & 1.71 & 3998 & 0.4884 & 2.12 \\
\hline
\end{tabular}

In table 3 is shown the distribution of offspring from incompatible matings when only those born after their dam had had at least one incompatible pregnancy, were taken into account. None of the chi-square values were significant. In the NSST breed there was, however, a deficiency of $\mathrm{Ca}+$ offspring, which was close to significance. This observation was consistent with the result obtained with the complete material. 


\section{Discussion}

The present study, which is based on a very large amount of family data, has not revealed any major deviation from expected segregation ratios for any of the 15 blood group factors studied. For all factors the results support the conclusions that (a) their mode of inheritance is Mendelian, (b) the blood typing methods are accurate, and (c) there is no evidence of large net differences in viability between the phenotypes studied. However, the extensive data available enabled the detection of even minor deviation from expectation. Two observations were found to be of main interest. Firstly, an overall excess of heterozygous offspring appeared in both types of matings in the ST breed and in compatible matings in the NST breed. Secondly, a majority of factors showed a deficit of $+/$ - offspring from incompatible matings in the NST breed.

In order to reduce the problem of distinguishing between true and false significances when large numbers of chi-square tests are performed, we have chosen to concentrate on interpreting the results obtained on pooled data and in the homogeneity test. A significant effect in incompatible or compatible matings which is not sufficiently strong to cause a significance in the pooled data or in the homogeneity test has been considered as not conclusive. It should be noted that a significant homogeneity chisquare due to a smaller proportion of $+/-$ offspring from incompatible matings than from compatible matings may be interpreted as evidence of maternal-fetal incompatibility of blood groups.

The significant $(P<0.05)$ chi-square obtained when all 79,455 matings studied in the ST breed were pooled (table 1) seems to reflect an overall excess of heterozygous offspring in this breed. It is noteworthy that all factors either segregated in close agreement with expectation or gave a small excess of heterozygotes when data were pooled over mating types. No single factor gave a noticeable deficit of $+/$ - offspring. The data on compatible matings in the NST breed also indicated an excess of heterozygous offspring. This slight deviation from expected segregation ratios may be caused by a weak selection affecting the blood groups investigated. With available data it is not possible to determine whether the excess of heterozygotes observed reflects a selective advantage of the heterozygote over both homozygotes, like in a balanced polymorphism, or is due to an additive effect of the dominant allele. Another more likely explanation of the observed results is that they reflect a weak positive effect of heterozygosity at chromosomal segments marked by the different blood group alleles.

The hypothesis that the observed excess of heterozygotes preferably reflects the effect of heterozygosity at chromosomal segments marked by blood group variants rather than effects at the blood group loci themselves could be tested since data on nine electrophoretic loci are available on the horses investigated in the present study. These systems are all codominant and therefore better suited for testing the proportion of heterozygous offspring from different types of matings. Such an analysis will be the subject of a subsequent paper.

A prime purpose of the present study was to investigate if any indication of the well-known maternal-fetal incompatibility of blood groups in horses could be revealed in this very extensive material. The factors $\mathrm{Aa}$ and $\mathrm{Qa}$ are responsible for the great majority of cases of neonatal isoerythrolysis in foals (STORMONT, 1975 ; SUzUKI, 1978 ; BAILEY, 1982). Therefore it is interesting to note that just these 2 factors were the ones 
for which the excess of heterozygous offspring appeared to be particularly pronounced ; $\mathrm{Aa}$ and $\mathrm{Qa}$ were consistently in excess in both breeds and mating types except for Qa in incompatible matings in the NST breed. We have encountered a small number of NI cases (all due to the Aa factor) in the ST breed during about 17 years of blood typing service but our records do not allow a serious estimate of the overall incidence of the disease in this breed. We have not observed any case of NI in the NST breed. In the present study there was no indication of a maternal-fetal incompatibility with respect to Aa. On the contrary, the excess of $\mathrm{Aa}+$ offspring from incompatible matings approached significance $\left(\chi_{1}^{2}=3.42 ; \mathrm{P}<0.10\right)$ when data were pooled over breeds. Neither for the Qa factor was there in the ST breed any sign of an incompatibility between mother and offspring, but instead a clear excess of heterozygous offspring from incompatible matings. These observations make it very unlikely that NI is the cause of any of the deviating segregation ratios found in the present study.

Our results with respect to $\mathrm{Aa}$ and $\mathrm{Qa}$ cannot be explained by the occurrence in the material of a large proportion of offspring from early parities, as there is no departure from Mendelian ratios with respect to Aa and Qa among offspring in the restricted material either (table 3). One exception to this is the Qa factor in the NST breed for which there is a slight deficiency. The number of matings involved was, however, very small.

The fact that we dit not find in our data any indication of a maternal-fetal incompatibility effect with respect to $\mathrm{Aa}$ and $\mathrm{Qa}$, may be ascribed to a number of possible reasons. The incidence of NI may be too low to be revealed by the test applied. It can be calculated that with the statistical test applied a difference of 5-20 p. 100 in viability between phenotypes should be detected, depending on the number of matings studied. Thus the test is not very sensitive to small differences in viability. Another possibility is that there was a small loss of offspring due to NI but that another mechanism compensated for this loss so that no net effect was detectable.

While in the ST breed no indication of an overall maternal-fetal incompatibility of blood groups was found, such a mechanism seemed to occur in the NST breed. In the latter breed a majority of factors in incompatible matings either exhibited a deficit of $+1-$ offspring or segregated close to expectation. Only the Aa factor deviated from this pattern with a noticeable excess of heterozygotes. When data were pooled over factors the deficit reached significance at the 5 p. 100 level (table 2). In the material restricted to dams with at least one prior incompatible pregnancy, the deficit was of the same magnitude, although not statistically significant (table 3). Among compatible matings there was no deficit, but instead a slight excess of heterozygotes. The homogeneity chisquare therefore was significant $(P<0.05)$, suggesting that an incompatibility of blood groups between mother and offspring may exist in the NST breed.

As already stated it is quite obvious that a possible incompatibility effect revealed by the segregation data cannot be caused by NI. One reason for this conclusion is that we have not encountered a single case of NI in the NST breed during about 17 years of blood typing work. However, immunological incompatibility may manifest itself through other mechanisms, yet unknown in the horse.

Naturally occurring antibodies directed against erythrocyte antigens is one possible basis for such a mechanism. With regard to $\mathrm{Ca}$, the factor with the most pronounced deficit of $+/-$ offspring in the NST breed, it is a well-known fact that anti-Ca antibodies occur very frequently if not in all mares which do not possess the $\mathrm{Ca}$ antigen (ScotT, 1978). All of the $27 \mathrm{Ca}$ - mares in the study by BAILEY (1982) had anti-Ca antibodies, 
some in a rather high titer, both in serum and colostrum. In spite of this, foals which were allowed to nurse those mares did not develop NI. Also from other studies (ScotT \& JeFFCOTT, 1978) it is clear that the $\mathrm{Ca}$ antigen is not a common cause of NI.

On the basis of a great number of experiments on livestock, including the horse (Podlachoux \& Dikov, 1970), it can be concluded that erythrocyte blood group antigens are most likely not present on spermatozoa (see Matousek, 1979). A possible selection against $\mathrm{Ca}+$ progeny based on maternal-fetal incompatibility of blood type is therefore likely to take place on the zygote or early foetus rather than on the spermatozoa. Such a selection may very well be associated with impaired fertility. In this context it is interesting to note that the overall conception rate in the NorthSwedish Trotter is quite low. Only 50-60 p. 100 of the mares covered each year give birth to a live foal.

The North-Swedish Trotter has a considerably smaller population size with an ensuing higher risk of inbreeding than the Swedish Trotter. The 2 breeds also have quite different genetic background and breed structure. These facts may well explain the difference in maternal-fetal incompatibility of blood groups, observed in this study.

Three more factors, namely $\mathrm{Ab}, \mathrm{Ka}$ and $\mathrm{Pb}$ gave significant homogeneity chisquares in the ST breed (table 1). As regards $\mathrm{Ab}$ and $\mathrm{Ka}$ the difference was in the direction suggesting maternal-fetal incompatibility which a deficit of $+/$ - offspring from incompatible matings and an excess from compatible matings. For $\mathrm{Pb}$ the difference was in the opposite direction. It cannot be excluded that these significances represent true deviations from expected segregation ratios. However, in the absence of a reasonable explanation for the deviations, for the time being we consider them fortuitous.

The present results represent a larger body of blood group segregation data than has been available in the horse hitherto. The 2 populations of horses involved, will be continuously monitored with regard to a number of blood groups and other polymorphic systems and in a few years a similarly large set of independent segregation data will be available. It will then hopefully be possible to confirm or reject the results of this study.

Received June 17, 1986. Accepted August 26, 1986.

\section{Acknowledgements}

The authors thank Prof. Jan RENDEL for valuable comments on the paper and the staff of the Blood Typing Unit at the Department of Animal Breeding and Genetics for skillful technical assistance. Financial support was provided by the Swedish Racing Board. 


\section{References}

BaILEy E., 1982. Prevalence of anti-red blood cell antibodies in the serum and colostrum of mares and its relationship to neonatal isoerythrolysis. Am. J. Vet. Res., 43, 1917-1921.

Bernstein F., 1929. Variations- und Erblichkeitstatistik. In : Baur E., Hartmann M. (Eds.), Handbuch der Vererbungswissenschaft, 52-54, Gebrüder Borntraeger, Berlin.

Bruner D.W., Hull F.E., Edwards P.R., Doll E.R., 1948. Icteric foals. J. Amer. Vet. Med. Ass., 112, 440-441.

Carolı J., Bessis M., 1947. Sur la cause et le traitement de l'ictère grave des muletons nouveaunés. C. R. Acad. Sci. Paris, 224, 969.

Coombs R.R.A., Crowhurst R.C., Day F.T., Heard D.H., Hinde I.T., Hoogstraten J., Parry H.B., 1948. Haemolytic disease of newborn foals due to isoimmunization of pregnancy. $J$. Hyg., 46, 403-418.

Cronin M.T.I., 1955. Haemolytic disease of newborn foals. Vet. Rec., 67, 479-494.

Franks D., 1962. Horse blood groups and hemolytic disease of the newborn foal. Ann. N. Y. Acad. Sci., 97, 235-250.

MATOUSEK J., 1979. Immunogenetic systems in the reproduction of livestock animals (mammals). Proc. I6th Int. Conf. Anim. Blood Grps biochem. Polymorphism, Leningrad, August 14thI8th, 1978, I, 3-53, ISABR.

Noda H., Watanabe Y., 1975. Relationships between blood groups and hemolytic disease of newborn foal. Jpn. J. Zootech. Sci., 46, 180-184.

Podlachouk L., Dikov V., 1970. Erythrocytic antigens on horses spermatozoa. Proc. 1lth Eur. Conf. Anim. Blood Grps Biochem. Polymorphism, Warsaw, July 2nd-6th, 1968, 463-466. Polish Scientific Publishers, Warsaw.

SANDBERG K., 1974. Blood typing of horses : current status and application to identification problems. Proc. Ist World Congr. Genet. applied to Livestock Prod., Madrid, October 7th11th, 1974, 1, 253-265. Editorial Garsi, Madrid.

SandBerg K., Andersson L., 1984. Genetic linkage in the horse. I. Linkage relationships among 15 blood marker loci. Hereditas, 100, 199-208.

SANDBerg K., ANDersson L., 1985. Studies on segregation of blood group factors in horses. Anim. Blood Grps Biochem. Genet., 14, suppl. 1, 22-23.

Scort A.M., 1978. Principal red-cell antigens responsible for haemolytic disease of the newborn foal : naturally-occurring antibodies in Thoroughbreds. J. Roy. Soc. Med., 71, 581-585.

Scott A.M., JefFCotT L.B., 1978. Haemolytic disease of the newborn foal. Vet. Rec., 103, 71-74.

Smith C., Jensen E.L., Baker L.N., Cox D.F., 1968. Quantitative studies on blood group and serum protein systems in pigs. I. Segregation ratios and gene frequencies. J. Anim. Sci., 27, 848-855.

Stormont C., 1975. Neonatal isoerythrolysis in domestic animals : a comparative review. Adv. Vet. Sci., 19, 23-46.

Suzukı Y., 1978. Studies on blood groups of horses. Memoirs of the Tokyo University of Agriculture, 20, 1-50. 